\title{
Geomagnetic disturbances driven by solar activity enhance total and cardiovascular mortality risk in 263 U.S. cities
}

Carolina Leticia Zilli Vieira ${ }^{1 *} \mathbb{D}$, Danilo Alvares ${ }^{2}$, Annelise Blomberg ${ }^{1}$, Joel Schwartz' ${ }^{1}$ Brent Coull ${ }^{3}$, Shaodan Huang ${ }^{1}$ and Petros Koutrakis ${ }^{1}$

\begin{abstract}
Background: Short-term geomagnetic disturbances (GMD) driven by the quasi-periodic 11-year cycle of solar activity have been linked to a broad range of adverse health effects, including cardiovascular diseases (CVD) and total deaths. We conducted a large epidemiological study in 263 U.S. cities to assess the effects of GMD on daily deaths of total, CVD, myocardial infarction (MI), and stroke.

Methods: We employed a two-step meta-analysis approach, in which we estimated city-specific and seasonstratified mortality risk associated with a GMD parameter (Kp index) in 263 U.S. cities. In addition, sensitivity analysis was performed to assess whether effect modification of particulate matter $\left(\mathrm{PM}_{2.5}\right)$ in the prior day changed $\mathrm{Kp}$ index effects on daily deaths after adjusting for confounders.

Results: We found significant association between daily GMD and total, CVD, and MI deaths. The effects were even stronger when we adjusted the models for 24-h $\mathrm{PM}_{2.5}$ for different seasons. For example, in the winter and fall one standard deviation of Z-score Kp index increase was associated with a 0.13 and $0.31 \%$ increase in total deaths, respectively (Winter: $p=0.01$, 95\% Cl: 0.02 to 0.24 ; Fall: $p=0.00001 ; 95 \%$ Cl: 0.23 to 0.4 ), without adjusting for $\mathrm{PM}_{2.5}$. The effects of GMD on total deaths were also observed in spring and summer in the models without $\mathrm{PM}_{2.5}(p=$ $0.00001)$. When the models were adjusted for $\mathrm{PM}_{2.5}$ the total deaths increased $0.47 \%$ in winter $(p=0.00001,95 \% \mathrm{Cl}$ : 0.3 to 0.65 ) and by $0.23 \%$ in fall ( $p=0.001,95 \% \mathrm{Cl}: 0.09$ to 0.37 ). The effects of GMD were also significant associated with $\mathrm{Ml}$ deaths and CVD. No positive significant association were found between Kp and stroke. The GMD effects on deaths were higher than for $24 \mathrm{~h}-\mathrm{PM}_{2.5}$ alone, especially in spring and fall.
\end{abstract}

Conclusion: Our results suggest that GMD is associated with total, CVD and MI deaths in 263 U. S cities. Increased mortality in the general population during GMD should be further investigated to determine whether those human physiological dynamics driven by variations in solar activity can be related to daily clinical cardiovascular observations.

Keywords: Geomagnetic disturbances, Health outcomes, Cardiovascular diseases, Epidemiology

\footnotetext{
* Correspondence: cazilli@hsph.harvard.edu

${ }^{1}$ Department of Environmental Health at Harvard School of Public Health,

401 Park Drive, Landmark Center 4th floor West (HSPH), 420 room, Boston,

MA 02215, USA

Full list of author information is available at the end of the article
}

(c) The Author(s). 2019 Open Access This article is distributed under the terms of the Creative Commons Attribution 4.0 International License (http://creativecommons.org/licenses/by/4.0/) which permits unrestricted use, distribution, and reproduction in any medium, provided you give appropriate credit to the original author(s) and the source, provide a link to the Creative Commons license, and indicate if changes were made. The Creative Commons Public Domain Dedication waiver (http://creativecommons.org/publicdomain/zero/1.0/) applies to the data made available in this article, unless otherwise stated. 


\section{Introduction}

Life on Earth has been long shaped by the continuous exposure to environmental electromagnetic fields. Exchange of energy between the solar wind-plasma and Earth's magnetic field (EMF) is driven by the quasi-periodic 11-year cycle of solar activity, which generates short-term geomagnetic disturbances (GMD). GMD affect the physiology, standard metabolism and behavior pattern of humans and other species (e.g., birds, whales, reptile, insects, bacteria) [1]. Short-term GMD have been associated with a broad range of adverse health effects, including cardiovascular diseases (CVD), neurological system diseases, behavioral diseases, and total deaths [1-29].

CVD, such as myocardial infarction (MI), coronary heart diseases, and stroke, continue to be the major cause of death for all regions worldwide [30]. Heart diseases have been the first leading causes of death since 1900 in the United States, with stroke among the 50 leading causes of death every year since 1924 [30, 31]. Cornelissen et al. (2002) showed an additional risk of MI mortality of 5\% during years of high solar activity compared to years of low activity in Minnesota, USA [2]. Recently, Vencloviene et al. (2014) evaluated the association between GMD and the survival of 1413 hospitalized patients with acute coronary syndromes in Lithuania [3]. Active GMD episodes during the second day after admission increased the hazard ratio by 1.58 times for cardiovascular death compared with geomagnetic quiet days [3].

Alabdulgader et al. (2018) found that not only solar wind intensity was correlated with increase in heart rate variability (HRV), but also the intensity of cosmic rays, solar radio flux, and Schumann resonance power were all associated with increased HRV and parasympathetic activity in a small health cohort in Hofuf, Saudi Arabia [28]. Sympathetic and parasympathetic nervous system activity of the autonomic nervous system (ANS) (Involuntary Nervous System) regulate functions such as the HRV, breathing, and metabolic processes in the body (U.S. National Library of Medicine, 2018). Low HRV is associated with a $32-45 \%$ increased risk of a first cardiovascular event in populations without known CVD [32], and is a predictor for sudden cardiac death that is responsible for about $25 \%$ of deaths in clinical cardiology [33].

In contrast to the positive associations discussed above Stoupel et al. (1994) observed highly significant negative correlation between daily paroxysmal atrial fibrillation (intermittent, rapid involuntary contractions of the heart muscle) and GMD activity $(r=-0.976, p=0.02)$ [34]. The absolute number of daily admissions for paroxysmal atrial fibrillation was higher on geomagnetic activity I days (lower GMD activity) than level IV (higher GMD activity) days $(p<0.004)$, and stroke admissions showed the same highly significant negative correlation with increasing geomagnetic activity, but only in males of 65 years or less $(r=-0.99, p=0.0008)$ [34]. Moreover, blood pressure and drastic changes in the circadian rhythm (biological 24-h circadian clock) have been reported during geomagnetic disturbances [2]. Circadian rhythm is a set of physiological and behavioral processes that exhibit a synchronized pattern with the day/night cycle periods. Shumilov et al. (2003) report that episodes of both high and extremely low levels of GMD are related to adverse effects on human health [6].

While research groups from Israel [13, 15, 24], Italy [18], Bulgaria [8-11], Mexico and Cuba [4], Canada [1], and the U.S. [2] have shown evidences of the connection between GMD and CVD deaths and other outcomes in relatively small cohorts, there is a need to determine the temporal and spatial impact of short term exposure to GMD on deaths in a large epidemiological study including CVD deaths. Consequently, we conducted a large national epidemiological study to investigate the acute effects of GMD on total and cause-specific mortality in 263 U.S. cities. In addition, we investigated the potential confounding and/or modifying effects of particulate matter with an aerodynamic diameter less than $2.5 \mu \mathrm{m}$ $\left(\mathrm{PM}_{2.5}\right)$ on GMD effects.

\section{Methods \\ Population}

Our study included daily total deaths, CVD, MI, and stroke deaths among all ages and gender from 263 U.S. cities (Fig. 1). We analyzed 2,008,990 days with 44,220,261 deaths in the study period over approximately 30 years. The mortality data up to 2006 were obtained from the National Center for Health Statistics (NCHS) website, and for years 1985 through 2013 from the Departments of Public Health for each city. The city coordinates, timeperiod mortality data and the total recorded deaths for each city are presented in the Additional file 1: Table S1 and Table S3). The causes of death were categorized according to the International statistical Classification codes of Diseases and Related Health Problems, Tenth Edition, as follows: all cardiovascular diseases (ICD10th, I00-I99), stroke deaths (ICD-10th, I60-I69), MI (ICD-10th, I21-I23-8), and total non-accidental deaths. Complete description of ICD-10th causes of deaths is in the Additional file 1.

\section{Environmental data}

Daily local weather data were obtained from the National Oceanic Atmospheric Administration's (NOAA), National Climatic Data Center. Ambient temperature and relative humidity were selected a priori based on their known associations with the outcomes or exposures [35-37]. Daily space weather data including Kp index, ap [nanoTesla (nT)] and sunspot number were downloaded from NASA Goddard Space Flight Center's 


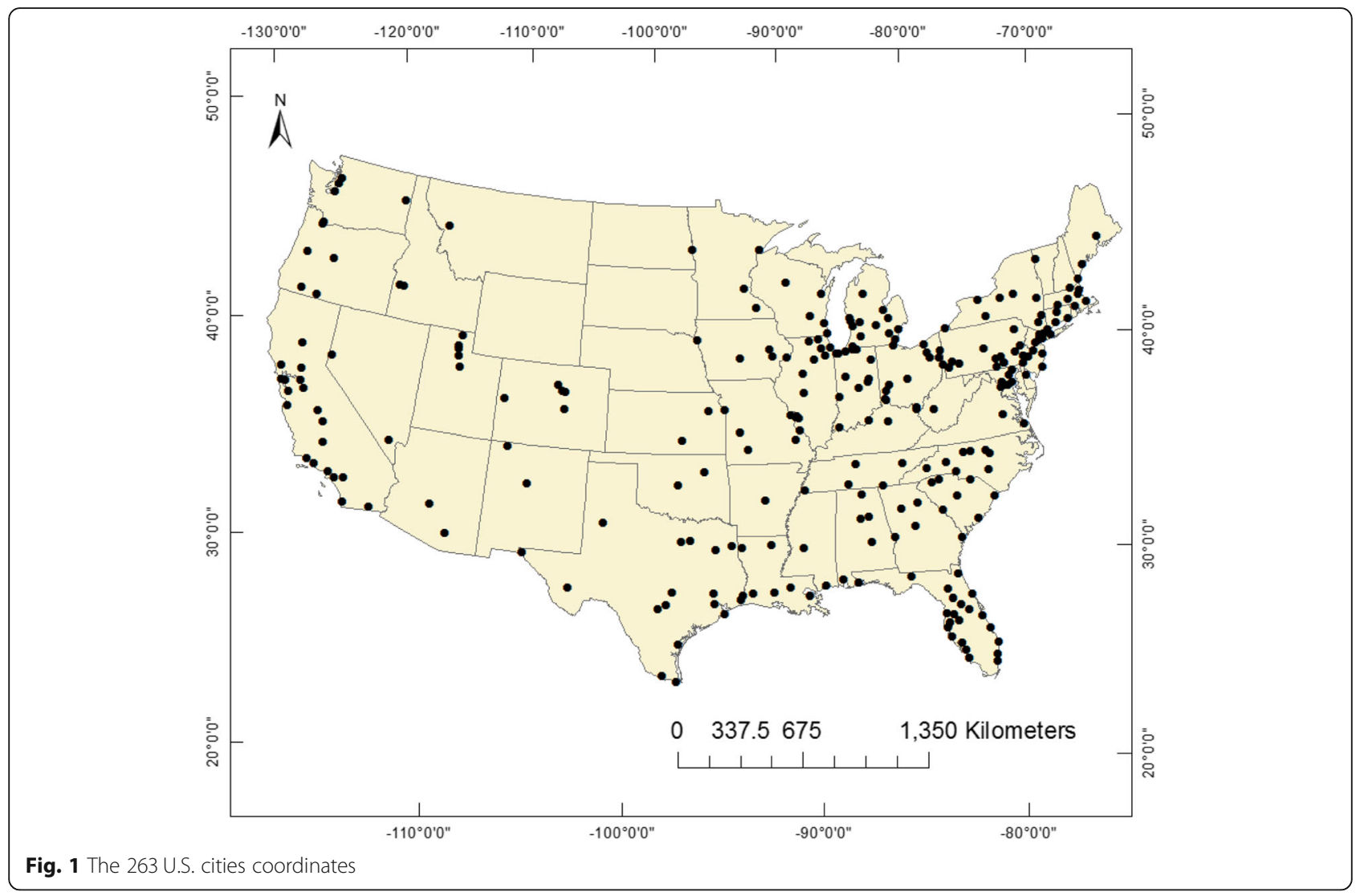

Space Physics (https://omniweb.gsfc.nasa.gov/form/dx1.html) (Figs. 2 and 3). OMNI 2 is a NASA space weather dataset recorded mostly from the ACE and WIND spacecraft located in the dayside magnetopause. High-energy GMD is directly associated with an increase in the solar activity, in which sunspot number is a parameter.
Kp index is a planetary GMD parameter generated by electric currents and the magnetic deviations on the ground (NOAA, 2019) (Fig. 3) [38]. The 3-h (h) ap (equivalent range in $\mathrm{nT}$ unit) index is derived from the $\mathrm{Kp}$ index, defined as the earliest occurring maximum 24-h value obtained by computing an 8-point running

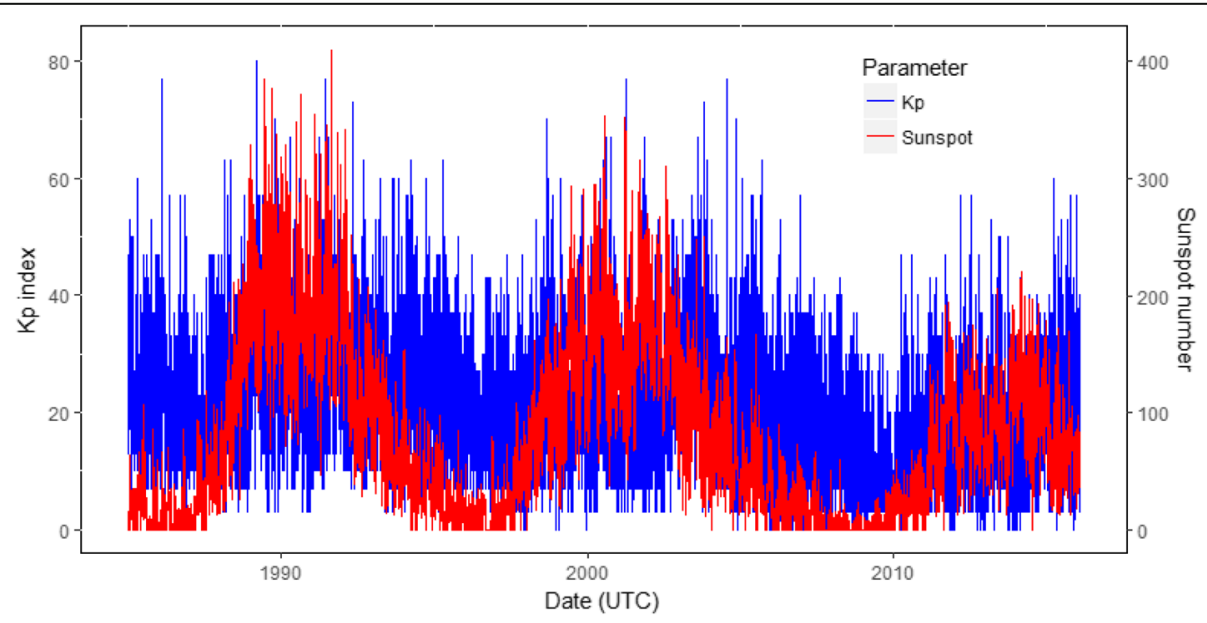

Note: $r=0.2, p<0.0001$

Fig. 2 Daily sunspot number and Kp index distribution. Note: $r 0.2, p<0.0001$ 


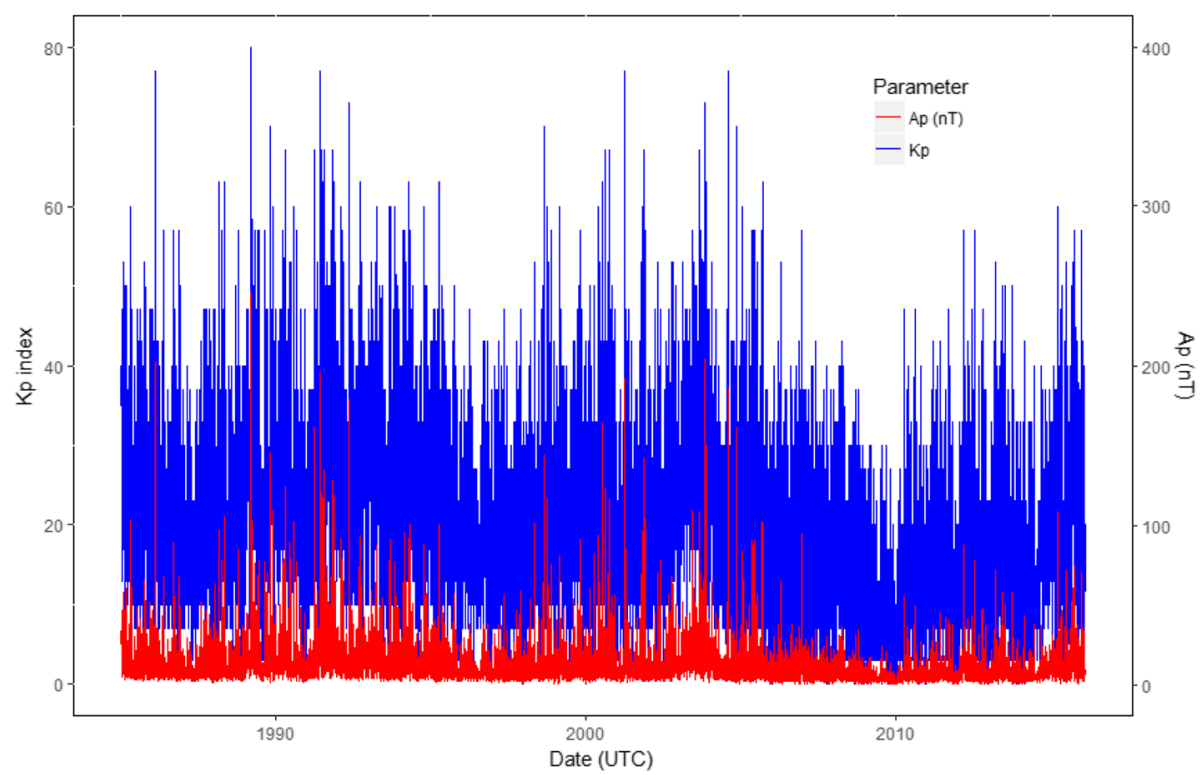

Note: $\mathrm{r}=0.34, p<0.0001$

Fig. 3 Daily Kp index and the equivalent Ap in nanoTesla (nT) distribution. Note: $r 0.34, p<0.0001$

average of successive 3-h ap indices uniquely associated with the storm event (NOAA, 2019). Kp values range from 0 (no disturbance) to 9 (maximum disturbance) in $1 / 3$ increment reported 8 times a day at 3 -h intervals recorded in Coordinated Universal Time (UTC). We used daily Kp sum, which is the sum of $24 \mathrm{~h}$ 3-h intervals of Kp data in UTC were converted to local time for each city $i$.

Daily $\mathrm{PM}_{2.5}$ values for each city were calculated using a model that standardizes daily measurements for all monitors within a city boundary and prevents missing days from one monitor from adding false variability to the daily value as previously described in Zanobetti \& Schwartz, 2009 [39, 40]. Acute exposure to $\mathrm{PM}_{2.5}$ was calculated as the mean of $24-\mathrm{h} \mathrm{PM}_{2.5}$ concentrations.

\section{Statistical analysis}

We estimated the effects of GMD on mortality risks in 263 U.S. cities using a generalized additive models (GAM) with a quasi-Poisson link function to account for over-dispersion. The models were fitted using cityaveraged variables including smooth functions (splines) with 1.5 or 2 degrees of freedom: day of the year (DOY) (1-365/366), daily ambient temperature (temp) $\left({ }^{\circ} \mathrm{C}\right)$, and daily ambient relative humidity (RH) (\%). Additional analyses were performed to investigate the impact of wind speed [WSPD (mph)] and planetary boundary layer height. Day of the week (DOW) (from Sunday to Saturday) and year were also included in the models. Seasons were defined as winter (December-February), spring
(March-May), summer (June-August), and fall (September-November). The generic structure these models can be represented as:

$$
\begin{aligned}
E\left(Y_{t}\right)= & \alpha+\beta_{i, s} * K p_{i, s}+g_{1.5}\left(D O Y_{t}\right)+g_{2}(\text { temp }) \\
& +g_{2}(R H)+\omega_{\text {day }, s} * D O W_{t}+\lambda_{s} * \text { year }
\end{aligned}
$$

where for each city and season, $E\left(Y_{t}\right)$ is the expected deaths at day $t ; \alpha$ is an intercept parameter; $K p_{i, s}$ is the Kp index of the city $i$ at season $s$ and $\beta_{i, s}$ its respective coefficient; $D O W_{t}$ is a factor variable that represents the day of week at time $t$ and $\omega_{d a y, s}$ is its coefficient for each factor level/day at season $s$; and year corresponds to the year and has $\lambda_{s}$ as coefficient at season $s$. The $g_{d f}(\cdot)$ function represents smoothing splines with $d f$ degrees of freedom. For a sensitivity analysis of the above model, we also included $\mathrm{PM}_{2.5}$ modeled through smoothing splines with 2 degrees of freedom to account for potential confounding by $\mathrm{PM}_{2.5}$. The $\mathrm{z}$-score transformation, $\mathrm{z}=\left(\mathrm{x}-\mu_{\mathrm{x}}\right) / \sigma_{\mathrm{x}}$, was employed for all continuous variables.

In the second stage, we used a mixed-effects metaanalysis model to estimate the overall $\mathrm{Kp}$ index mortality effect for each season. The model can be written as follows:

$$
E\left(\hat{\beta}_{i, s}\right)=\gamma_{s}+u_{i, s}
$$

where $\hat{\beta}_{i, s}$ is the estimated $\mathrm{Kp}$ index coefficient for city $i$ at season $s$ (see model 1) and $\gamma_{s}$ represents the overall Kp index mortality effect (intercept) at season $s$. The 
city-specific random effects are represented by $u_{i, s}$, which satisfies $u_{i, s} \sim N\left(0, \sigma_{u}^{2}\right)$.

Based on model (1), the overall $\mathrm{Kp}$ index mortality effect at each season is calculated by:

$$
\mathrm{Eff}_{\mathrm{s}}=\exp \left(c * \hat{\gamma}_{s}\right),
$$

where $\hat{\gamma}_{s}$ represents the Kp index estimated intercept in (2) and $c$ is a predefined increment of $\mathrm{Kp}$ index at season $s$. Throughout this work, we consider $c=1$ as one standard deviation of $\mathrm{z}$-score Kp index. Pearson correlation analysis was used to describe the relation between $\mathrm{Kp}$, ap and sunspot number (Figs. 2 and 3). All analyses were performed in $\mathrm{R}$ software 3.4.3.

\section{Results}

Our study included up to 2,008,990 days with data for mortality, Kp index, temperature, and relative humidity from 263 cities. The mean daily total mortality was 14 deaths/day, with winter having 16 deaths/day, spring with 14 deaths/day, summer with 13 deaths/day and fall having 14 deaths/day, including 44,220,261 deaths in the study period. The mean daily Kp index was $16.5(\sim 428$ $\mathrm{nT})$, with the highest seasonal average levels in spring $(17.3$ or $\sim 758 \mathrm{nT})$ and fall $(17$ or $\sim 758 \mathrm{nT})$ and lowest in winter and summer (15.8 or $\sim 410 \mathrm{nT})$. The number of GMD storms was higher in spring and fall (Table 1). Kp index was correlated with sunspot and ap $(p<$ 0.0001 ) (Figs. 2 and 3). Summary statistics are presented in Table 1.

Table 2 presents the estimated percent increase in mortality for each standard deviation increase in z-score $\mathrm{Kp}$ index. Overall, we found statistically significant associations $(p<0.05)$ between daily GMD and total, CVD, and MI deaths. The results were even stronger when adjusted for 24-h average $\mathrm{PM}_{2.5}$ concentration in different seasons (Fig. 4). The effects of the exposure to GMD on total, CVD, and MI deaths in the day of event were similar or higher than the exposure to 24-h $\mathrm{PM}_{2.5}$ especially in spring and fall (Fig. 4). In winter, the association between GMD and total, CVD and MI deaths were significantly larger in the models adjusted for $\mathrm{PM}_{2.5}$. No significant associations were observed between $24 \mathrm{~h}$ $\mathrm{PM}_{2.5}$ and CVD and MI alone (Fig. 4).

We found that an increase of $0.13 \%$ in total mortality in winter $(p=0.01 ; 95 \% \mathrm{CI}: 0.02$ to 0.24$), 0.31 \%$ in spring ( $p=0.00001 ; 95 \% \mathrm{CI}: 0.21$ to 0.41$), 0.27 \%$ in summer ( $p=0.00001 ; 95 \%$ CI: 0.16 to 0.37$)$, and $0.31 \%$ increase in total deaths in fall season $(p=0.00001 ; 95 \%$ CI: 0.23 to 0.4 ) for one standard deviation increase in $\mathrm{z}$-score $\mathrm{Kp}$ index in the models without adjusting for $\mathrm{PM}_{2.5}$. When adjusted for $\mathrm{PM}_{2.5}$, total deaths increased by $0.47 \%$ for each standard deviation of $\mathrm{z}$-score $\mathrm{Kp}$ index increase in winter $(p=0.00001 ; 95 \% \mathrm{CI}: 0.3$ to $0.65), 0.22 \%$ in summer $(p=0.00001 ; 95 \% \mathrm{CI}: 0.05$ to $0.4)$, and $0.23 \%$ in fall ( $p=0.001 ; 95 \%$ CI: 0.09 to 0.37$)$. No statistically significant associations were found between GMD and total deaths in spring in the models adjusted for $\mathrm{PM}_{2.5}$ (Table 3 ).

The analysis of the effects of GMD on CVD and MI deaths showed statistically significant associations in spring and fall seasons in the models without adjusting for $\mathrm{PM}_{2.5}$. CVD mortality increased by $0.21 \%$ for one standard deviation of $\mathrm{z}$-score $\mathrm{Kp}$ index increase in spring ( $p=0.008 ; 95 \%$ CI: 0.05 to 0.37 ), and by $0.34 \%$ in fall $(p=0.00001 ; 95 \%$ CI: 0.23 to 0.44$)$. In the models

Table 1 Summary of daily death counts and environmental parameters included in the analysis

\begin{tabular}{|c|c|c|c|c|c|}
\hline Variable & Overall & Winter & Spring & Summer & Fall \\
\hline Daily Mortality (deaths/day) & Mean (SD) & & & & \\
\hline Total & $15.3(21.5)$ & $15.7(23.7)$ & $14.4(21.4)$ & $13.3(20)$ & $13.9(20.7)$ \\
\hline CVD & $5(8.3)$ & $5.4(9.3)$ & $4.9(8.3)$ & $4.5(7.6)$ & $4.6(7.9)$ \\
\hline $\mathrm{Ml}$ & $1.2(2.4)$ & $1.4(2.7)$ & $1.3(2.4)$ & $1.1(2.2)$ & $1.2(2.3)$ \\
\hline STROKE & $1(1.6)$ & $1.03(1.7)$ & $0.9(1.6)$ & $0.8(1.5)$ & $0.9(1.5)$ \\
\hline \multicolumn{6}{|l|}{ Environmental Parameters } \\
\hline Temperature $\left({ }^{\circ} \mathrm{C}\right)$ & $14.2(10.1)$ & $3.9(8.5)$ & $13.6(7.7)$ & $23.9(4.26)$ & $15.07(7.6)$ \\
\hline Z-score & $0(1.0)$ & $-1.04(0.8)$ & $-0.05(0.7)$ & $0.9(0.4)$ & $0.1(0.7)$ \\
\hline Relative Humidity (\%) & $66.2(16.2)$ & $69.4(16.1)$ & $69.5(15.7)$ & $62.1(16.6)$ & $65.8(15.6)$ \\
\hline Z-score & $0.01(1.0)$ & $0.2(1.0)$ & $-0.25(1.0)$ & $0.01(0.9)$ & $0.1(0.9)$ \\
\hline Kp_index & $16.5(9.4)$ & $15.8(9.1)$ & $17.3(9.6)$ & $15.8(8.8)$ & $17(10.0)$ \\
\hline Z-score & $0.02(1.0)$ & $-0.05(0.9)$ & $0.1(1.0)$ & $-0.05(0.9)$ & $0.07(1.0)$ \\
\hline Number of GMD storms (Kp index > 5; ap index > 29) & 936,368 & 154,316 & 290,004 & 212,180 & 279,868 \\
\hline 24-h Average $\mathrm{PM}_{2.5}\left(\mu \mathrm{g} / \mathrm{m}^{3}\right)$ & $12.6(7.5)$ & $13.0(7.8)$ & $11.2(6.2)$ & $14.3(8.2)$ & $12(7.4)$ \\
\hline Z-score & $0.05(1.0)$ & $0.13(1.0)$ & $-0.13(0.8)$ & $0.2(1.1)$ & $-0.04(1.0)$ \\
\hline
\end{tabular}


Table 2 Estimated daily percent increase in mortality $(95 \% \mathrm{Cl})$ associated with one standard deviation of z-score Kp index

\begin{tabular}{lllll}
\hline & Total & CVD & Ml & Stroke \\
\hline Winter & $0.13(0.02,0.24)^{*}$ & $-0.04(-0.22,0.13)$ & $0.21(-0.07,0.5)$ & $-0.74(-0.96,-0.51)^{* * * *}$ \\
Spring & $0.31(0.21,0.41)^{* * * *}$ & $0.21(0.05,0.37)^{* *}$ & $0.4(0.05,0.72)^{*}$ & $-0.03(-0.4,0.33)$ \\
Summer & $0.27(0.16,0.37)^{* * * *}$ & $0.15(-0.01,0.33)$ & $0.14(-0.2,0.5)$ & $-0.52(-0.14,-0.9)^{* *}$ \\
Fall & $0.31(0.23,0.4)^{* * * *}$ & $0.34(0.23,0.44)^{* * * *}$ & $0.7(0.43,0.94)^{* * * *}$ & $0.06(-0.3,0.4)$ \\
\hline
\end{tabular}

${ }^{*} p$-value $<0.05 ;{ }^{* *} p<0.001 ;{ }^{* * *} p<0.0001 ;{ }^{* * * *} p<0.00001$
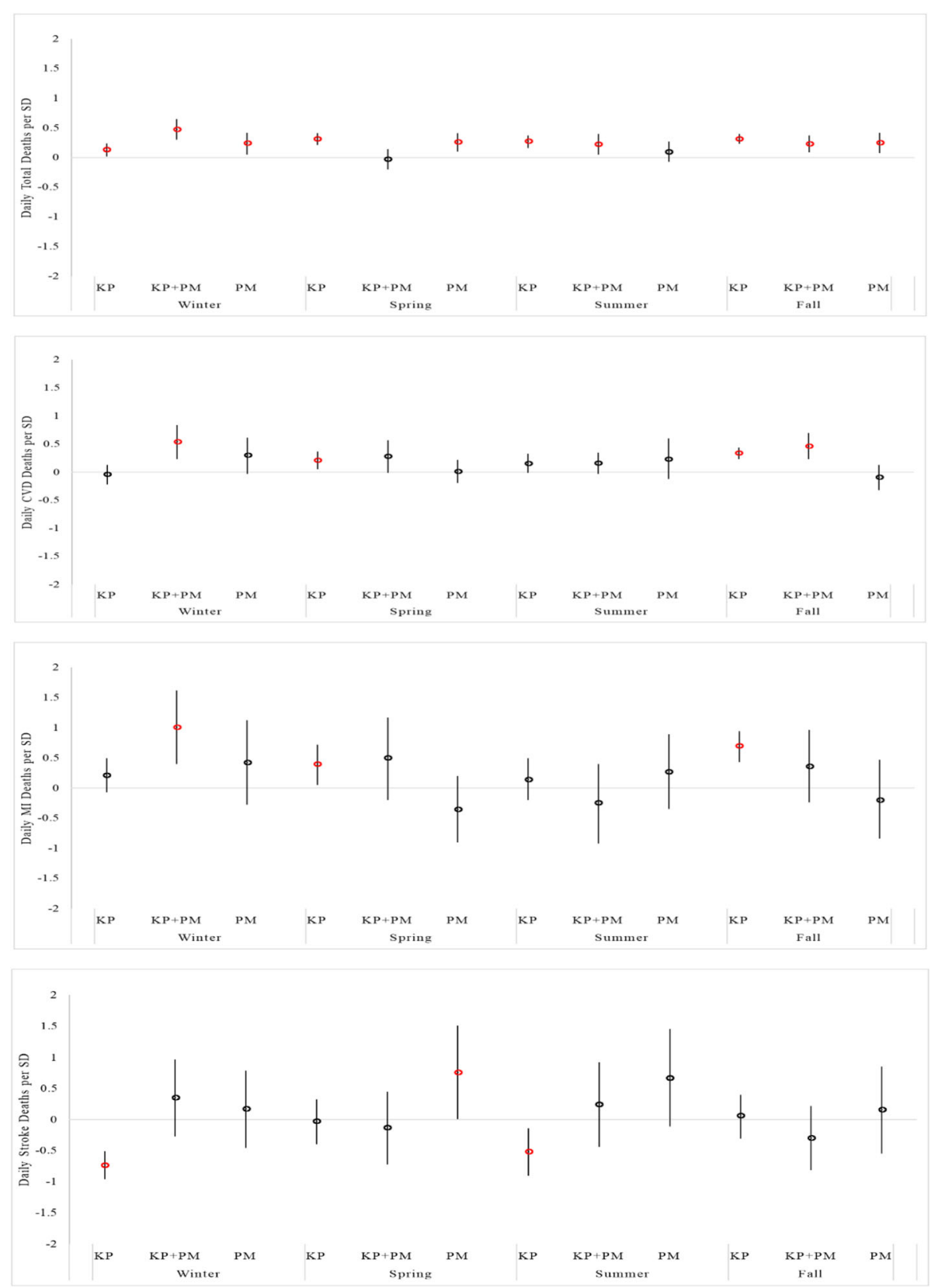

Fig. 4 Daily city-specific and season-stratified mortality risk from the exposure to one standard deviation of z-score Kp index, Kp index adjusted for 24-h PM2.5, and only 24-h PM2.5. The models were also adjusted for daily temperature (oC), daily relative humidity (\%), and day of the year (1-365/366), day of the week (DOW), year for each season (winter, spring, summer, and fall) 
Table 3 Estimated percent increase in mortality $(95 \% \mathrm{Cl}$ ) associated with one standard deviation of z-score Kp index adjusted for $\mathrm{PM}_{2.5}$

\begin{tabular}{lllll}
\hline & Total & CVD & Ml & Stroke \\
\hline Winter & $0.47(0.3,0.65)^{* * * *}$ & $0.54(0.23,0.84)^{* * *}$ & $1.0(0.4,1.62)^{* * *}$ & $0.35(-0.27,0.97)$ \\
Spring & $-0.03(-0.2,0.14)$ & $0.28(-0.01,0.57)$ & $0.5(-0.2,1.17)$ & $-0.13(-0.72,0.45)$ \\
Summer & $0.22(0.05,0.4)^{* *}$ & $0.16(-0.03,0.35)$ & $-0.25(-0.92,0.4)$ & $0.24(-0.44,0.92)$ \\
Fall & $0.23(0.09,0.37)^{* *}$ & $0.46(0.23,0.7)^{* * * *}$ & $0.36(-0.24,0.96)$ & $-0.3(-0.81,0.22)$ \\
\hline
\end{tabular}

${ }^{*} p$-value $<0.05 ;{ }^{* *} p<0.001 ;{ }^{* * *} p<0.0001 ;{ }^{* * * *} p<0.00001$

adjusted for $\mathrm{PM}_{2.5}$, the CVD deaths increased by $0.54 \%$ in winter ( $p=0.0005$; $95 \%$ CI: 0.23 to 0.84 ) and by $0.46 \%$ in fall ( $p=0.00001 ; 95 \%$ CI: 0.23 to 0.7$)$ for one standard deviation of $\mathrm{z}$-score Kp index increase. No statistically significant associations were found in spring and summer seasons in the models adjusted for $\mathrm{PM}_{2.5}$ (Table 3).

One standard deviation of $\mathrm{z}$-score $\mathrm{Kp}$ index increased MI deaths by $0.4 \%$ in spring ( $p=0.02 ; 95 \%$ CI: 0.05 to $0.72)$ and by $0.7 \%$ in fall $(p=0.00001 ; 95 \%$ CI: 0.43 to 0.94), without adjusting for $\mathrm{PM}_{2.5}$. When the models were adjusted for $\mathrm{PM}_{2.5}$, MI deaths increased $1.0 \%$ for each standard deviation of $\mathrm{z}$-score $\mathrm{Kp}$ index in winter $(p=0.0001 ; 95 \%$ CI: 0.4 to 1.62$)$. No significant associations were found in other seasons (Table 3). For stroke deaths, GMD was negatively significantly associated in winter, spring and summer (Table 2). No significant associations were found between GMD and stroke after adjusting for $\mathrm{PM}_{2.5}$ (Table 3). The inclusion of WSPD and HPBL in the models had no effect on the associations found between GMD and mortality rates.

\section{Discussion}

Overall, this study suggests that GMD increases cityspecific and season-stratified total, CVD, and MI deaths in the selected 263 U.S. cities (Fig. 2). The effects were stronger when we adjusted the models for $\mathrm{PM}_{2.5}$ for different seasons. In these models, the associations between GMD and CVD and MI were only statistically significant in winter, indicating that both predictors are important for this season. Previous epidemiological studies described higher incidence of CVD mortality in winter in elderly patients $[41,42]$. In addition, while numerous studies of environmental exposure risk have described the seasonal impact of $\mathrm{PM}_{2.5}$ on mortality rates [43], this study shows that short-term effects of GMD on total, CVD, and MI deaths were similar to or stronger than the effects of $24 \mathrm{~h}-\mathrm{PM}_{2.5}$ exposures.

The effects of GMD on total deaths were found in all seasons, and on CVD and MI deaths in spring and fall. Also in spring and fall, the effects of GMD on total, CVD, and MI deaths were higher than for $\mathrm{PM}_{2.5}$ alone. Seasonal short-term GMD variability is notably stronger during equinoctial seasons [44, 45]. Major GMD, also known as geomagnetic storms, occur when variations in the solar wind driven by solar activity transfer energy from the solar wind into Earth's magnetosphere. Earth's magnetosphere is a highly dynamic area around the planet that responds dramatically to solar variations by producing changes in the radiation belts, changes in the ionosphere, and in the environmental electric currents (NOAA, 2018). Diurnal earth magnetic field variations can range between few tens of nT to $100-500 \mathrm{nT}$ over a $72 \mathrm{~h}$ period. Increased equinoctial GMD may explain the higher impact of GMD on mortality rates in spring and fall.

The direct impact of environmental electric and magnetic fields produced during GMD [46] on the human ANS may explain the effects of GMD on total, CVD, and MI deaths found in our study. Interactions between GMD with ANS are likely to induce a cascade of reactions in the body's electrophysiology that culminate in the collapse of organ functions and death. Studies have described the mechanisms by which GMD may regulate ANS and body systems via a magneto-reception system [47]. Magneto-reception is a sense which allows living beings to detect EMF variations. EMF may trigger quantum chemical reactions in photosensitive retina proteins called cryptochromes and/or within magneto-receptors in cells containing magnetite (magnetic mineral iron) that activate specific structures of the central nervous system, such as the suprachiasmatic nucleus and the ANS [47]. The overlap between diurnal cycle of solar radiation and episodes of GMD on photo/magnetoreceptors may over-stimulate functioning of the central nervous system and disrupt the standard 24-h circadian rhythm processes, playing a dramatic role in the regulation of cardiovascular physiology and other systems [48]. The close alignment between the geomagnetic activity rhythms and the electrophysiology of the human body has been observed in ultrasound waves from heart structures [echocardiogram (ECG)], in brain waves (electroencephalogram [EEG)], and peripheral nerve activity that is controlled by the ANS $[1,2,4]$.

In this context, increased GMD is likely to activate in humans: (1) the photo/magneto-reception system, including the ferromagnetic receptors and the cryptochrome protein [14-16, 27]; (2) cell membrane excitability (thermal noise), by the enhancement of ionic motion, signaling, and accumulation in ion channels, with primary focus on 
intracellular $\mathrm{Ca}^{+2}$; (3) the surface charges and small electric currents (as electric fields) among cells with capacity to distort the membrane shape; (4) the chemical bonds via radical-pair-reaction; (5) the production of reactive oxygen species (ROS) or reactive nitrogen species (RNS), inducing acute and chronic episodes of oxidative stress that contribute to many pathological conditions; (6) regulation of melatonin secretion and 24-h circadian rhythm disruption [14-16, 48-50]. These processes appear to be mutually dependent.

$\mathrm{Ca}^{2+}$ regulates many aspects of cell function, including energy metabolism, signal transduction, hormonal regulation, cellular motility, and apoptosis [51, 52]. In cardiac cells, the GMD-photo/magnetoreceptors-ANS may induce prolonged cardiac action potential (change in voltage across cardiac cell membrane), activating intracellular $\mathrm{Ca}^{2+}$ overload through voltage-gated $\mathrm{Ca}^{2+}$ channels. Increased intracellular $\mathrm{Ca}^{2+}$ accumulation activates the calcium-sensor protein called calmodulin that regulates the e.g. plasma membrane $\mathrm{Ca}^{2+}$ pump, intracellular $\mathrm{Ca}^{2+}$ dependent proteins, and enzyme expression including adenylyl cyclase (AC) [53]. AC produce cyclic adenosine monophosphate (cAMP), which controls protein kinase A (PKA) activity [54]. cAMP is a second messenger that regulates the function of ion channels across the cell membranes. The activity of AC-cAMP/PKA generates spontaneous action potential [54]. Dysregulation of ANS and increased expression of AC-cAMP/PKA lead to cardiac dysrhythmias and arrhythmias [53, 54], which have been interrelated with several abnormal arrhythmia-related conditions including acute myocardial infarction, congestive heart failure, diabetic neuropathy and sudden cardiac death [55-57]. Patients with congestive heart failure have high incidence of sudden cardiac death attributed to lethal cardiac arrhythmias [57]. A recent study found that ANS activity presents strongly synchronized patterns with the time-varying magnetic fields associated with the geomagnetic field and Schumann resonances (atmospheric electric fields) in a small healthy cohort [29]. The same group demonstrated that GMD was strongly correlated with increased parasympathetic activity and HRV [28].

Previous epidemiological studies have found significant associations between GMD and both MI and CVD deaths $[2-4,20]$. In Lithuania, Vencloviene et al. (2014) showed that high GMD during the second day after admission increased the hazard ratio by 1.58 times for cardiovascular death compared with quiet days [3]. Patients with impaired cardiovascular system functions demonstrated deterioration in capillary blood flow during high GMD [3]. They also observed that increased GMD may modify the association between short-term nitrogen dioxide $\left(\mathrm{NO}_{2}\right)$ exposure and emergency hospitalization for acute coronary syndrome (ACS) [3]. Mendonza et al. (2004) observed that MI events were statistically significantly associated with GMD (ap > $50 \mathrm{nT}$ ) in five large hospitals at Havana [21]. Moreover, Stoupel et al. (1994) found stroke deaths were negatively significantly associated with GMD [34]. These results are similar with our findings.

Studies have suggested that animal and human standard physiology are synchronized with EMF, being highly sensitive to its unpredictable GMD oscillations. The deep penetration of earth magnetic field into living tissues and cells added to the increase of atmospheric electric field variations during GMD may deeply modify the circadian rhythm processes and recovery properties of human body, leading to its collapse and death. Future studies are needed to quantify the synchronization between diurnal and nocturnal EMF with human electrophysiology during different intensities of GMD periods, which may be related to daily clinical cardiovascular observations. The comprehension of the cyclic impact of natural environmental risk factors driven by solar activity on human health is fundamental to understand evolutionary and adaptive aspects of life on Earth.

\section{Conclusion}

Overall, this study suggests that GMD increase daily total, CVD, and MI deaths, even fitting models with 24-h $\mathrm{PM}_{2.5}$. The GMD effects on deaths were higher than for $\mathrm{PM}_{2.5}$ alone especially in spring and fall. Increased mortality in the general population during GMD should be further investigated to determine whether those human physiological dynamics driven by variations in solar activity can be related to daily clinical cardiovascular observations.

\section{Additional file}

Additional file 1: Table S1. ICD-10th edition classification for all causes of deaths. Table S1a. ICD-10th edition classification for diseases of the circulatory system. Table S2. City coordinates and time-period mortality data. Table S3. City-recorded deaths (DOCX 107 kb)

\section{Acknowledgements}

The authors would like to thank the study participants for their dedicated participation. The authors would like to thank Mike Wolfson and ChoongMin Kang for their assistance in collecting and managing data for this study.

\section{Authors' contributions}

CLZV and PK designed research; CLZV and PK performed research; DA, JS, PK, $A B, S H$ and $B C$ contributed with the statistical analysis design and $R$ code development; CLZV analyzed data and wrote the manuscript; all authors read and approved the final manuscript.

\section{Authors' information}

Carolina Leticia Zilli Vieira: Dr. Vieira is Research Associate in the Department of Environmental Health at the Harvard School of Public Health since 2015.

She investigates the impact of environmental electromagnetic radiation and air pollution on human health.

Danilo Alvares: Dr. Alvares is Professor of statistics in Chile. His research is focused on Bayesian statistics, particularly joint models for longitudinal and time-to-event data, longitudinal analysis, and computational methods. Annelise Blomberg: Annelise Blomberg is Ph. D candidate in the Department of Environmental Health at the Harvard School of Public Health. 
Joel Schwartz: Dr. Schwartz is Professor of Environmental Epidemiology at the Harvard School of Public Health. He is interested in epidemiology looking at the health consequences of exposure to pollutants, including lead in water. He is also interested in statistical methods such as the modeling of continuous covariates in epidemiologic studies, regression spline models, nonparametric smoothing, generalized additive models, mixed and hierarchical models, case-crossover techniques, and time series studies. Brent Coull: Dr. Coull is Professor of Biostatistics in the Department of Biostatistics at the Harvard School of Public Health. Dr. Coull's current research interests fall into the broad areas of categorical data analysis and semiparametric regression modeling. Recent topics in the analysis of categorical data include capture-recapture mixture models, random effect models for multiple discrete binary outcomes, confidence intervals for a binomial proportion, and order-restricted methods for stratified contingency tables. In the area of semiparametric regression modeling, he has focused on the development of such models for complex data structures often encountered in public health settings, such as cross-over and longitudinal settings.

Shaodan Huang: Dr. Huang is Post-Doc researcher at the Environmental Health, Harvard School of Public Health. Her work is focus on indoor environment. Their current project is 'Air pollution mixtures: health effects across life stages'

Petros Koutrakis: Dr. Koutrakis is Professor of Environmental Sciences at the Harvard School of Public Health. Dr. Koutrakis' research activities focus on the development of human exposure measurement techniques and the investigation of sources, transport, and the fate of air pollutants. Dr. Koutrakis has conducted a number of comprehensive air pollution studies in the United States, Canada, Spain, Chile, Kuwait, Cyprus and Greece that investigate the extent of human exposures to gaseous and particulate air pollutants. Other research interests include the assessment of particulate matter exposures and their effects on the cardiac and pulmonary health. Dr. Koutrakis is the Head of the Exposure, Epidemiology and Risk Program and the Director of the EPA/Harvard University Center for Ambient Particle Health Effects.

\section{Funding}

USEPA grants RD-83479801 and RD-83587201. Its contents are solely the responsibility of the grantee and do not necessarily represent the official views of the USEPA. Further, USEPA does not endorse the purchase of any commercial products or services mentioned in the publication.

\section{Availability of data and materials}

The datasets used and/or analyzed during the current study are available from the corresponding author on reasonable request.

\section{Ethics approval and consent to participate}

All data derived from human subjects are commercially available data aggregated by ZIP code or census tract and is thus not considered human subjects research.

\section{Consent for publication}

All authors approved the manuscript and this submission.

\section{Competing interests}

The authors declare that they have no competing interests.

\section{Author details}

'Department of Environmental Health at Harvard School of Public Health, 401 Park Drive, Landmark Center 4th floor West (HSPH), 420 room, Boston, MA 02215, USA. ${ }^{2}$ Department of Statistics, Pontifical Catholic University of Chile, Santiago, Chile. ${ }^{3}$ Department of Biostatistics, Harvard School of Public Health, Boston, USA

Received: 28 February 2019 Accepted: 9 August 2019 Published online: 11 September 2019

\section{References}

1. Caswell JM, Carniello TN, Murugan NJ. Annual incidence of mortality related to hypertensive disease in Canada and associations with heliophysical parameters. Int J Biometeorol. 2016;60(1):9-20.
2. Cornélissen G, Halberg F, Breus T, Syutkina EV, Baevsky R, Weydahl A, et al. Non-photic solar associations of heart rate variability and myocardial infarction. J Atmos Sol Terr Phys. 2002;64(5):707-20.

3. Vencloviene J, Babarskiene R, Milvidaite I, Kubilius R, Stasionyte J. The effect of solar-geomagnetic activity during and after admission on survival in patients with acute coronary syndromes. Int J Biometeorol. 2014;58(6):1295-303.

4. Mendoza B, Díaz-Sandoval R. Relationship between solar activity and myocardial infarctions in Mexico city. Geofis Int. 2000;39(1):1-4.

5. Dimitrova S, Mustafa FR, Stoilova I, Babayev ES, Kazimov EA. Possible influence of solar extreme events and related geomagnetic disturbances on human cardio-vascular state: results of collaborative Bulgarian-Azerbaijani studies. Adv Space Res. 2009;43(4):641-8.

6. Shumilov OI, Kasatkina EA, Enykeev AV, Chramov AV. Study of geomagnetic activity influence on a fetal state using cardiotocography. Biofizika. 2003; 48(2):355-60.

7. Gurfinkel II, Kuleshova VP, Oraevskii VN. Assessment of the effect of a geomagnetic storm on the frequency of appearance of acute cardiovascular pathology. Biofizika. 1998;43(4):654-8.

8. Dimitrova S. Relationship between human physiological parameters and geomagnetic variations of solar origin. Adv Space Res. 2006;37:1251-7.

9. Dimitrova $S$, Stoilova I. Human physiological reaction to geomagnetic disturbances of solar origin. In: Wilson A, editor. Proceedings of the 10th European solar physics meeting solar variability: from Core to outer Frontiers (ESA SP-506 Vol. 1). Noordwijk: ESA Publications Division; 2002. p. 129-32.

10. Dimitrova S, Stoilova I. Planetary geomagnetic indices, human physiology and subjective complaints. J Balkan Geophys Soc. 2003;6(1):37-45.

11. Dimitrova S. Different geomagnetic indices as an indicator for geo-effective solar storms and human physiological state. J Atmos Sol Terr Phys. 2008; 70(2):420-7.

12. Katsavrias C, Preka-Papadema P, Moussas X, Apostolou T, Theodoropoulou A, Papadima T. (2013). Helio-geomagnetic influence in cardiological cases. Adv Space Res. 2013;51(1):96-106.

13. Stoupel E, Babayev ES, Abramson E, Sulke J. Days of "zero" leve geomagnetic activity accompanied by the high neutron activity and dynamics of some medical events - antipodes to geomagnetic storms. Health. 2013;5(05):855

14. Knox EG, Armstrong E, Lancashire R, Wall M, Haynes R. Heart attacks and geomagnetic activity. Nature. 1979;281(5732):564-5.

15. Stoupel E, Kalediene R, Petrauskiene J, Starkuviene S, Abramson E, Israelevich $\mathrm{P}$, Sulkes J. Twenty years study of solar, geomagnetic, cosmic ray activity links with monthly deaths number (n-850304). J Biomed Sci Eng. 2011:4(06):426.

16. Malin SRC, Srivastava BJ. Correlation between heart attacks and magnetic activity. Nature. 1979;277(5698):646-8

17. Feigin VL, Parmar PG, Barker-Collo S, Bennett DA, Anderson CS, Thrift AG, Stegmayr B, Rothwell PM, Giroud M, Bejot $Y$, Carvil P, Krishnamurthi R, Kasabov N. Geomagnetic storms can trigger stroke: evidence from 6 large population-based studies in Europe and Australasia. Stroke. 2014; 45(6):1639-45.

18. Gavryuseva E, Kroussanova N, Simoniello R. Human state in connection with helio and geospheric perturbations. Proc Second Solar Cycle Space Weather Euroconfer. 2001:477:543-6.

19. Papailiou M, Mavromichalaki H, Vassilaki A, Kelesidis KM, Mertzanos GA, Petropoulos B. Cosmic ray variations of solar origin in relation to human physiological state during the December 2006 solar extreme events. Adv Space Res. 2009;43:523-9.

20. Taboada RER, Figueredo PS, Figueredo SS. Geomagnetic activity related to acute myocardial infarctions: relationship in a reduced population and time interval. Geofisica Int-Mexico. 2004:43(2):265.

21. Zenchenko TA, Dimitrova S, Stoilova I, Breus TK. Individual responses of arterial pressure to geomagnetic activity in practically healthy subjects. Klin Med. 2009;87(4):18-24

22. Azcárate T, Mendoza B, Levi JR. Influence of geomagnetic activity and atmospheric pressure on human arterial pressure during the solar cycle 24 . Adv Space Res. 2016:58(10):2116-25.

23. Campbell WH. Geomagnetic storms, the Dst ring-current myth and lognormal distributions. J Atmos Terr Phys. 1996;58(10):1171-87.

24. Rosenbaum BP, Weil RJ. Aneurysmal subarachnoid hemorrhage: relationship to solar activity in the United States, 1988-2010. Astrobiology. 2014;14(7):568-76. 
25. Stienen MN, Smoll NR, Battaglia M, Schatlo B, Woernle CM, Fung C, et al Intracranial aneurysm rupture is predicted by measures of solar activity. World Neurosurg. 2015;83(4):588-95.

26. Vencloviene J, Grazuleviciene R, Babarskiene R, Dedele A, Grazulevicius T. Short-term nitrogen dioxide exposure and geomagnetic activity interaction: contribution to emergency hospitalization for acute coronary syndrome. Int J Environ Health Res. 2011;21(3):149-60.

27. Palmer SJ, Rycroft MJ, Cermack M. Solar and geomagnetic activity, extremely low frequency magnetic and electric fields and human health at the Earth's surface. Surv Geophys. 2006;27(5):557-95.

28. Alabdulgader A, McCraty R, Atkinson M, Dobyns Y, Vainoras A, Ragulskis M, Stolc $V$. Long-term study of heart rate variability responses to changes in the solar and geomagnetic environment. Sci Rep. 2018;8(1):2663.

29. McCraty R, Atkinson M, Stolc V, Alabdulgader AA, Vainoras A, Ragulskis M. Synchronization of human autonomic nervous system rhythms with geomagnetic activity in human subjects. Int J Environ Res Public Health. 2017:14(7):770.

30. Roth GA, Johnson C, Abajobir A, Abd-Allah F, Abera SF, Abyu G, et al. Global, regional, and national burden of cardiovascular diseases for 10 causes, 1990 to 2015. J Am Coll Cardiol. 2017;70(1):1-25.

31. Sidney S, Quesenberry CP, Jaffe MG, Sorel M, Nguyen-Huynh MN, Kushi LH, et al. Recent trends in cardiovascular mortality in the United States and public health goals. JAMA Cardiol. 2016;1(5):594-9.

32. Hillebrand S, Hillebrand S, Gast KB, de Mutsert R, Swenne CA, Jukema JW, Middeldorp S, et al. Heart rate variability and first cardiovascular event in populations without known cardiovascular disease: meta-analysis and doseresponse meta-regression. Europace. 2013;15(5):742-9.

33. Sessa F, Anna V, Messina G, Cibelli G, Monda V, Marsala G, et al. Heart rate variability as predictive factor for sudden cardiac death. Aging. 2018;10(2):166

34. Stoupel E, Martfel JN, Rotenberg Z. Paroxysmal atrial fibrillation and stroke (cerebrovascular accidents) in males and females above and below age 65 on days of different geomagnetic activity levels. J Basic Clin Physiol Pharmacol. 1994;5(3-4):315-29.

35. Wilmshurst P. Temperature and cardiovascular mortality. BMJ. 1994;309: 1029-30.

36. Barnett AG. Temperature and cardiovascular deaths in the US elderly: changes over time. Epidemiology. 2007;18(3):369-72.

37. Schwartz J, Samet JM, Patz JA. Hospital admissions for heart disease: the effects of temperature and humidity. Epidemiology. 2004;15(6):755-61.

38. Kauristie K, Morschhauser A, Olsen N, Finlay CC, McPherron RL, Gjerloev JW, Opgenoorth $\mathrm{HJ}$. On the usage of geomagnetic indices for data selection in internal field modelling. Space Sci Rev. 2017;206(1-4):61-90.

39. Zanobetti A, Schwartz J. The effect of fine and coarse particulate air pollution on mortality: a national analysis. Environ Health Perspect. 2009. 117(6):898.

40. Blomberg AJ, Coull BA, Jhun I, Vieira CL, Zanobetti A, Garshick E, Schwartz J, Koutrakis P. Effect modification of ambient particle mortality by radon: a time series analysis in 108 US cities. J Air Waste Manage Assoc. 2019:69(3):266-76.

41. Sheth T, Nair C, Muller J, Yusuf S. Increased winter mortality from acute myocardial infarction and stroke: the effect of age. J Am Coll Cardiol. 1999; 33(7):1916-9.

42. Woodhouse PR, Khaw K, Plummer M, Meade TW, Foley A. Seasonal variations of plasma fibrinogen and factor VII activity in the elderly: winter infections and death from cardiovascular disease. Lancet. 1994; 343(8895):435-9.

43. Franklin $M$, Koutrakis $P$, Schwartz J. The role of particle composition on the association between PM2.5 and mortality. Epidimiology. 2008;19(5):680.

44. Lyatsky W, Newell PT, Hamza A. Solar illumination as cause of the equinoctial preference for geomagnetic activity. Geophys Res Lett. 2001; 28(12):2353-6.

45. Russell CA, McPherron RL. Semiannual variation of geomagnetic activity. J Geophys Res. 1973;78(1):92-108.

46. Schrijver CJ, Mitchell SD. Disturbances in the US electric grid associated with geomagnetic activity. J Space Weather Space Climate. 2013;3:A19.

47. Kirschvink $J$, Jones DS, MacFadden BJ. Magnetite biomineralization and magnetoreception in organisms: a new biomagnetism. Springer Science \& Business Media (Text book): 2013.

48. Cermakian N, Sassone-Corsi P. Environmental stimulus perception and control of circadian clocks. Curr Opin Neurobiol. 2002;12(4):359-65.
49. Martino TA, Oudit GY, Herzenberg AM, Tata N, Koletar MM, Kabir GM, Sole MJ. Circadian rhythm disorganization produces profound cardiovascular and renal disease in hamsters. Am J Physiol Regul Integr Comp Physiol. 2008; 294(5):R1675-83.

50. Burch JB, Reif JS, Yost MG. Geomagnetic disturbances are associated with reduced nocturnal excretion of a melatonin metabolite in humans. Neurosci Lett. 1999;266(3):209-12.

51. Huikuri HV, Castellanos A, Myerburg RJ. Sudden death due to cardiac arrhythmias. N Engl J Med. 2001;345(20):1473-82.

52. Catterall WA. Voltage-gated calcium channels. Cold Spring Harb Perspect Biol. 2011;3(8):a003947.

53. Chin D, Means AR. Calmodulin: a prototypical calcium sensor. Trends Cell Biol. 2000;10(8):322-8.

54. Behar J, Ganesan A, Zhang J, Yaniv Y. The autonomic nervous system regulates the heart rate through CAMP-PKA dependent and independent coupled-clock pacemaker cell mechanisms. Front Physiol. 2016;7:419.

55. Kapa S, Venkatachalam KL, Asirvatham SJ. The autonomic nervous system in cardiac electrophysiology: an elegant interaction and emerging concepts. Cardiol Rev. 2010;18(6):275-84.

56. Vaseghi M, Shivkumar K. The role of the autonomic nervous system in sudden cardiac death. Prog Cardiovasc Dis. 2008;50(6):404.

57. Bigger JJ. Why patients with congestive heart failure die: arrhythmias and sudden cardiac death. Circulation. 1987;75:IV28-35.

\section{Publisher's Note}

Springer Nature remains neutral with regard to jurisdictional claims in published maps and institutional affiliations.
Ready to submit your research? Choose BMC and benefit from:

- fast, convenient online submission

- thorough peer review by experienced researchers in your field

- rapid publication on acceptance

- support for research data, including large and complex data types

- gold Open Access which fosters wider collaboration and increased citations

- maximum visibility for your research: over $100 \mathrm{M}$ website views per year

At $\mathrm{BMC}$, research is always in progress.

Learn more biomedcentral.com/submissions 